\title{
Activation of Heat-Shock Transcription Factor by Graded Reductions in Renal ATP, In Vivo, in the Rat
}

Scott K. Van Why, Andrea S. Mann, Gunilla Thulin, Xiao-Hong Zhu, Michael Kashgarian, and Norman J. Siegel

Departments of Pediatrics and Pathology, Yale University School of Medicine, New Haven, Connecticut 06510

\begin{abstract}
Renal ischemia results in both a profound fall in cellular ATP and a rapid induction of the $70 \mathrm{kD}$ heat-shock protein family, HSP-70. The present studies examined the relationship between cellular ATP and induction of the stress response in renal cortex. Cellular ATP, continuously monitored by in vivo ${ }^{31} \mathrm{P}$-NMR spectroscopy, was reduced and maintained at specific, stable levels in renal cortex by partial aortic occlusion for $\mathbf{4 5} \mathbf{m i n}$. Activation of heat-shock transcription factor (HSF) was detected by gel retardation assay and transcription was confirmed by Northern analysis. Activation of HSF was not present, and HSP-70 mRNA induction did not occur when ATP levels were maintained above $60 \%$ preocclusion (control) levels. Reduction in cortical ATP levels to $35-50 \%$ preocclusion values resulted in HSF activation and low-level expression of inducible HSP-70 mRNA. Cellular ATP of 20-25\% control values resulted in a greater level of HSF activation and subsequent HSP-70 mRNA elaboration. HSF was activated at the end of $15 \mathrm{~min}$ of total occlusion. The studies indicate that a $50 \%$ reduction in cellular ATP in the renal cortex must occur before the stress response is detectable, that reduction of ATP below $25 \%$ control levels produces a more vigorous response, and that reperfusion is not required for initiation of a heatshock response in the kidney. Cellular ATP, or the metabolic consequences associated with ATP depletion, may be a threshold factor for initiation of a stress response in the kidney. (J. Clin. Invest. 1994. 94:1518-1523.) Key words: heat-shock proteins $\bullet$ transcription factors • ischemia $\bullet$ kidney $\bullet$ adenosine triphosphate.
\end{abstract}

\section{Introduction}

Renal injury that follows from ischemia is accompanied by a host of cellular metabolic, structural, and functional alterations that have been recently reviewed $(1,2)$. Much of this work has elucidated how ischemia results in cellular injury, and the direct consequences of that injury. Recent investigations have examined possible mechanisms by which cells may protect against further injury, or recover from injury already sustained. Because of their demonstrated cytoprotective effects in other models of

Address correspondence to Scott K. Van Why, Yale University School of Medicine, Department of Pediatrics, 333 Cedar Street, P.O. Box 208064, New Haven, CT 06520-8064.

Received for publication 22 March 1994 and in revised form 1 June 1994.

J. Clin. Invest.

(C) The American Society for Clinical Investigation, Inc.

0021-9738/94/10/1518/06 \$2.00

Volume 94, October 1994, 1518-1523 cell stress, their importance in intracellular protein trafficking, and their ability to reactivate denatured proteins $(3,4)$, attention has been focused on the inducible $70 \mathrm{kD}$ heat-shock protein, HSP-72 ${ }^{1}$, as a potentially important component of the cellular and molecular mechanisms responsible for restitution of postischemic cellular integrity. HSP-72 is rapidly induced by renal ischemia in a temporal and spatial pattern that suggests that this stress protein is instrumental in cellular recovery $(5,6)$. In studies of cultured renal cells, accumulation of the stress proteins has been associated with the cytoprotective effects of glycine and alanine (7), and protection of aerobic and anaerobic metabolism (8). The observation that HSP-72 induction protects the metabolic processes associated with ATP synthesis is particularly interesting, since ATP depletion is the hallmark of an ischemic insult. Cellular ATP, then, could be a link between the processes of injury and recovery from renal ischemia and decreased cellular ATP, or the metabolic consequences thereof could be a sensor for activation of a stress response.

In the kidney, severe ATP depletion from total vascular occlusion is associated with prompt elaboration of inducible HSP-70 mRNA and the protein HSP-72. However, the precise relationship of cellular ATP to the induction of the stress response has not been defined. In unstressed cells, preformed heat-shock transcription factor (HSF) exists in a monomeric form that has no DNA binding activity. With physiological stress, however, HSF forms a trimer and is thus activated to bind specific DNA sequences that make up the heat-shock element (HSE) $(9,10)$. Activated heat-shock transcription factors have been defined as those proteins that bind the NGAAN repeats which comprise the $\operatorname{HSE}(11,12)$ and represent the most proximate indication of an induced stress response. Since HSF retards the migration of these DNA sequences in nondenaturing gels, activation of HSF as shown by gel-retardation assays is a sensitive indicator of cell stress (11). To determine whether a relationship exists between ATP depletion and stress protein induction, we developed a model in which renal ATP could be reduced, in vivo, to predetermined steady-state levels and maintained throughout the ischemic interval. Evidence for subsequent induction of the stress response was determined by finding activation of HSF and confirmation of inducible HSP70 mRNA elaboration.

\section{Methods}

Animal preparation. 200-290 g male Sprague-Dawley rats were anesthetized with thiobutabarbital (Inactin; Byke Gulden, Konstanz, Germany) $(80 \mathrm{mg} / \mathrm{kg}$ i.p.), had an external jugular catheter placed, were given intravenous fluids, and then exposure of kidneys and hepariniza-

1. Abbreviations used in this paper: HSE, heat-shock element; HSF, heat-shock transcription factor; HSP-70, $70 \mathrm{kD}$ heat-shock protein family; HSP-72, inducible HSP-70 protein. 
tion were performed as previously described (5). Body temperature was maintained at $36.5-37.5^{\circ} \mathrm{C}$ throughout the experimental period by means of a recirculating water bath. A balloon-cuffed vascular occluder (In Vivo Metric, Healdsburg, CA) was placed around the aorta, distal to the celiac artery and proximal to the renal arteries. Arterial pressure distal to the vascular occluder was monitored via a femoral artery catheter and a blood pressure monitor (Gould Inc., Glen Burnie, MD). The cuff was inflated to reach a predetermined level of aortic occlusion as indicated by reduction in mean femoral artery pressure. Cortical ATP levels in the left kidney were monitored continuously with ${ }^{31}$ P-NMR spectroscopy throughout the experimental period. For protein and RNA isolation, cortex of the monitored kidney was harvested immediately at the end of the period of aortic occlusion or at reflow intervals up to 2 $\mathrm{h}$ after $\mathbf{4 5} \mathrm{min}$ of complete or partial occlusion. Sham operated animals were monitored with ${ }^{31} \mathrm{P}-\mathrm{NMR}$ and examined for HSF activation or HSP-70 mRNA expression at the same time points as experimental animals.

NMR spectroscopy. Cellular ATP levels in the renal cortex were monitored continuously, in vivo, using NMR spectroscopy as previously described (13). Spectra were collected before the occlusion interval and during the experimental period until kidney harvest for protein or RNA isolation. Thus, each animal served as its own control and ATP levels are expressed as percent preocclusion (control) values. Cortical ATP levels were obtained every 4.5 min throughout each study.

Gel-retardation assay. Renal cortex was harvested immediately at the end of the occlusion interval in all study groups and at $30 \mathrm{~min}$ and $2 \mathrm{~h}$ of reflow in animals subjected to complete occlusion. Total cellular protein was isolated by adapting methods described by Blake et al. (14). Tissue was homogenized at $0^{\circ} \mathrm{C}$ in $5 \mathrm{ml}$ of $20 \mathrm{mM}$ Hepes ( $\mathrm{pH} 7.9$ ), 400 $\mathrm{mM} \mathrm{NaCl}, 1.5 \mathrm{mM} \mathrm{MgCl}_{2}, 0.2 \mathrm{mM}$ EDTA, $20 \%$ glycerol, $0.2 \mathrm{mM}$ DTT, $0.5 \mathrm{mM}$ PMSF, $0.5 \mathrm{mM}$ leupeptin using a Potter-Elvehjem homogenizer. Cellular debris was pelleted for $30 \mathrm{~min}$ at $140,000 \mathrm{~g}$ in a centrifuge (Optima; Beckman Instruments, Inc., Fullerton, CA) at $4^{\circ} \mathrm{C}$. Protein concentrations of the supernatants were determined by protein assay (Bio-Rad Laboratories, protein assay Hercules, CA) and aliquots were stored at $-80^{\circ} \mathrm{C}$.

Two single-stranded complementary HSE fragment oligonucleotides containing the NGAAN repeats (15) were synthesized and then annealed in equimolar amounts in $20 \mathrm{mM}$ Tris (pH 7.5), $2 \mathrm{mM} \mathrm{MgCl}$, and 50 $\mathrm{mM} \mathrm{NaCl}$ at $95^{\circ} \mathrm{C}$ for $5 \mathrm{~min}$. DNA concentration was determined by ethidium bromide dot quantitation (16), and 50 pg double-stranded HSE fragment was end-labeled with T4 polynucleotide kinase (Promega Corp., Madison, WI) and ${ }^{32}$ P]ATP.

The gel retardation assay was adapted from Baler et al. (17). $10 \mu \mathrm{g}$ of the renal cortical protein extracts and $2 \mu \mathrm{g}$ of poly(dI-dC)-poly(dIdC) (Pharmacia Fine Chemicals, Piscataway, NJ) was placed in $30 \mu \mathrm{l}$ of binding buffer containing $12 \mathrm{mM}$ Hepes (pH 7.9), 12\% glycerol, 2 $\mathrm{mM} \mathrm{MgCl}{ }_{2}, 60 \mathrm{mM} \mathrm{KCl}, 0.12 \mathrm{mM}$ EDTA, $0.3 \mathrm{mM}$ PMSF, and 0.3 mM DTT. To this mixture was added either a 200 -fold molar excess of unlabeled HSE fragment, 200-fold molar excess of unrelated doublestranded DNA fragment (15), or a buffer blank. The reactions were incubated in parallel for $15 \mathrm{~min}$ at $25^{\circ} \mathrm{C}$ followed by addition to each tube of $20,000 \mathrm{cpm}$ of the end-labeled HSE fragment with an additional incubation for $25 \mathrm{~min}$. The samples were then electrophoresed at 35 $\mathrm{mA}$ through a nondenaturing $4.5 \%$ acrylamide gel in TGE (40 mM Tris [pH 8.0], $270 \mathrm{mM}$ glycine, $2 \mathrm{mM}$ EDTA) for $1.5 \mathrm{~h}$. The gels were dried and exposed to XAR-5 film (Eastman Kodak Co., Rochester, NY) at $-80^{\circ} \mathrm{C}$ with intensifying screens.

Northern analysis. Northern analysis for inducible HSP-70 mRNA as well as for the loading control 28S ribosomal RNA was performed on $30 \mu \mathrm{g}$ samples of total cellular RNA extracted from renal cortex at $2 \mathrm{~h}$ reflow after the occlusion interval. RNA extraction, blot preparation, hybridization conditions, and probes were as previously described (5).

\section{Results}

Heat-shock transcription factor activation from renal ischemia. Evidence of HSF activation to bind the heat-shock element

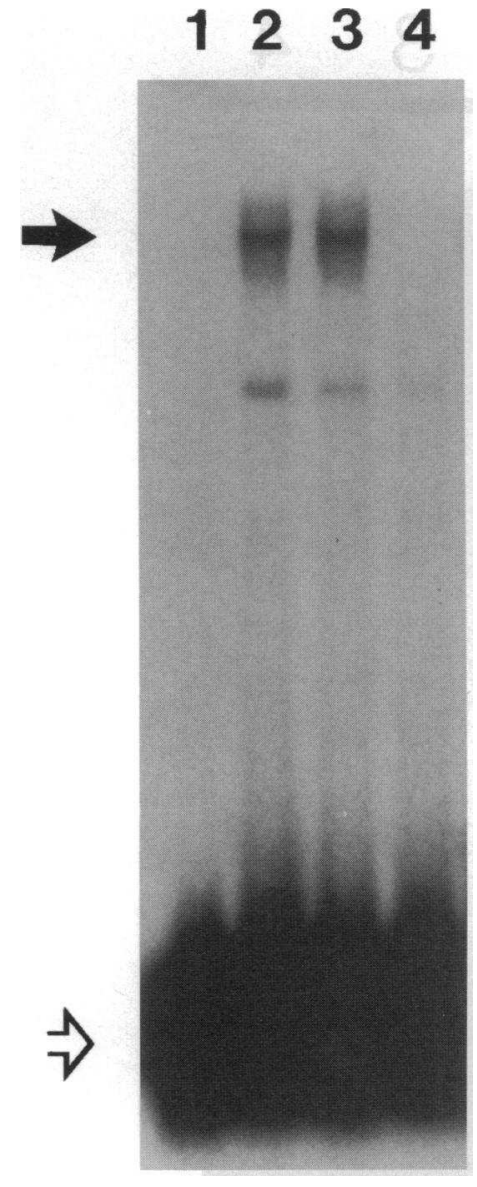

Figure 1. Representative gel retardation assay showing specificity of HSF-HSE interaction after $45 \mathrm{~min}$ of renal ischemia. (Open arrow) labeled HSE fragment, unbound to HSF and free to migrate through gel; (closed arrow) labeled HSE fragment bound by activated HSF; (lane 1 ) labeled HSF fragment alone, no incubation with cellular proteins; (lane 2) the labeled HSE fragment was incubated with total cellular protein from renal cortex after 45 min ischemia; (lane 3) prior to addition of labeled HSE, cellular protein was preincubated with excess nonspecific doublestranded DNA; (lane 4) preincubated with excess unlabeled HSE fragment. Activated HSF specifically binds HSE and retards the fragment in gel electrophoresis.

was first sought using the model of renal ischemia in which elaboration of inducible HSP-70 mRNA and HSP-72 protein has been well-characterized $(5,6)$. The specificity of the gelretardation assay to detect activated HSF is shown in Fig. 1. The more slowly migrating labeled HSE fragment corresponds to the previously described HSF-HSE complex after heat shock (11). HSF activated to bind HSE was present among cellular proteins after 45 min complete renal ischemia (lane 2). Activated HSF was not inhibited from binding to labeled HSE by preincubation with excess nonspecific double-stranded DNA (lane 3) but was competitively inhibited from binding HSE probe by preincubation with unlabeled HSE (lane 4), which indicated the specificity of the assay.

The elaboration of HSF activated to bind HSE after $45 \mathrm{~min}$ renal ischemia is represented in Fig. 2. In each experiment, parallel competitive preincubation with unlabeled HSE was performed (+ lanes). A small amount of HSF constitutively bound HSE in nonischemic control kidney (lane 1). At the end of the $45 \mathrm{~min}$ of ischemia, with no reflow, HSF was distinctly activated to bind HSE in greater quantity (lane 2). HSF-HSE interaction increased further at $30 \mathrm{~min}$ of reflow (lane 3), and had begun to decline by $2 \mathrm{~h}$ reflow (lane 4). Activation of HSF occurred rapidly and as early as $15 \mathrm{~min}$ into the ischemic interval (Fig. 3, lanes 2 and 3).

Vascular occlusion and cellular ATP levels in renal cortex. Graded vascular occlusion, as determined by change in mean arterial pressure distal to the constriction, resulted in a stepwise reduction in cellular ATP levels in the renal cortex. Representative experiments from four animals with different degrees of 


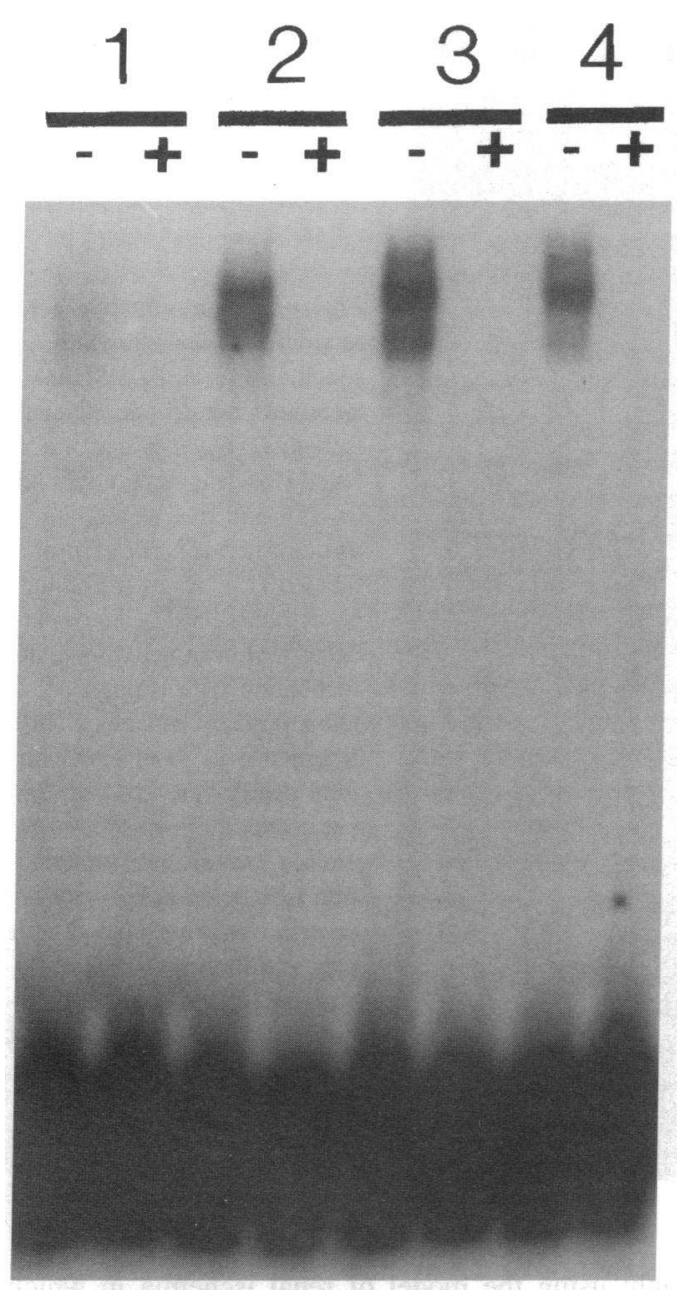

Figure 2. HSF activation after $45 \mathrm{~min}$ renal ischemia. $(+)$ preincubation of cortical extracts with excess cold HSE; (-) no competitive preincubation; (lane 1) nonischemic control; (lane 2) cortex harvested at end of $45 \mathrm{~min}$ ischemia; (lane 3) $30 \mathrm{~min}$ reflow after $45 \mathrm{~min}$ ischemia; (lane 4) $2 \mathrm{~h}$ reflow after $45 \mathrm{~min}$ ischemia.

aortic occlusion are shown in Fig. 4. No decline in ATP levels occurred in sham operated animals. With $50 \%$ occlusion, cortical ATP levels were $95 \%$ of preocclusion levels; $70 \%$ constriction reduced ATP to $70-80 \%$ of preocclusion; $90 \%$ constriction resulted in a fall in cellular ATP to 35-55\%; and total occlusion
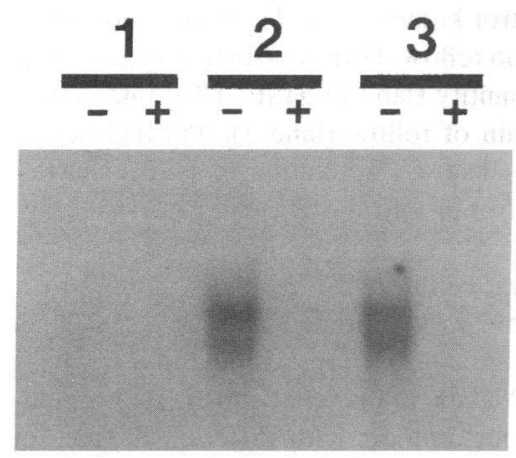

Figure 3. HSF activation after brief ischemia. $(+)$ competitive preincubation cold HSE; $(-)$ no competitive preincubation; (lane 1) nonischemic control; (lanes 2 and 3) $15 \mathrm{~min}$ ischemia, no reflow. The area of the gel shown is where the HSF-HSE complexes migrate. Free labeled oligonucleotide which migrated to the bottom of the gel is not shown.

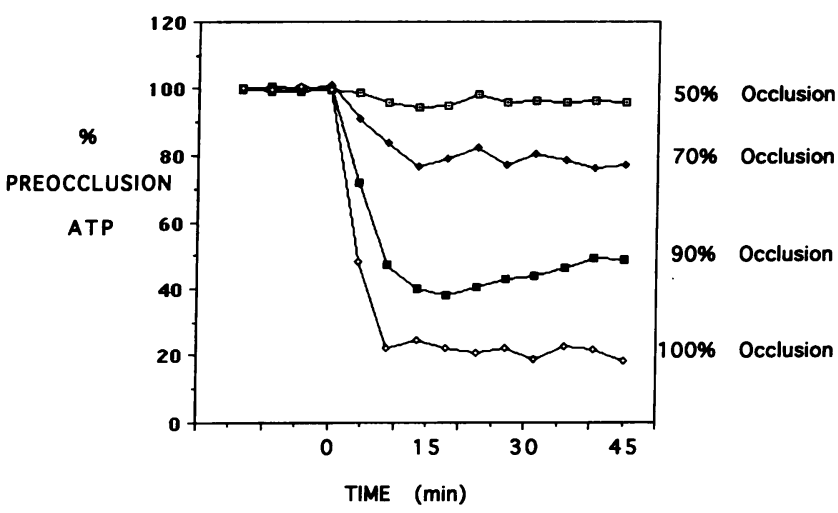

Figure 4. Cellular ATP in renal cortex as a function of graded vascular occlusion. Shown are representative experiments of four separate animals with different degrees of aortic occlusion, as indicated on the right. ATP levels are expressed as percent of preocclusion level for the same experimental animal. Time 0 is the onset of ischemia.

dropped ATP levels to 20-25\% of preocclusion values. Cellular ATP levels remained steady during occlusion, no progressive decline occurred over the 45-min interval. After the initial series of experiments which characterized the stable reduction in cortical ATP, subsequent studies were performed by targeting specific ATP levels. This was made possible by taking advantage of the rapid in vivo determination of cellular ATP with the current NMR techniques. A specific reduction in cellular ATP was selected and initially targeted by distal blood pressure monitoring. If the specific ATP decrement was not reached, occluder pressure could be adjusted rapidly to achieve the desired ATP level. Thus, the procedure allowed renal ATP levels to be clamped at specific reduced steady state values. Subsequent examination of renal cortex for activated HSF or for HSP-70 mRNA elaboration could be accomplished, then, and related to the level of cellular ATP achieved during vascular occlusion.

HSF activation and HSP-70 mRNA induction relative to cellular ATP. Renal cortex was harvested immediately at the end of $45 \mathrm{~min}$ of reduced cellular ATP and HSF activation was determined by gel-retardation assay (Fig. 5). Lanes 1-6 represent separate experiments with either no reduction in cellu-

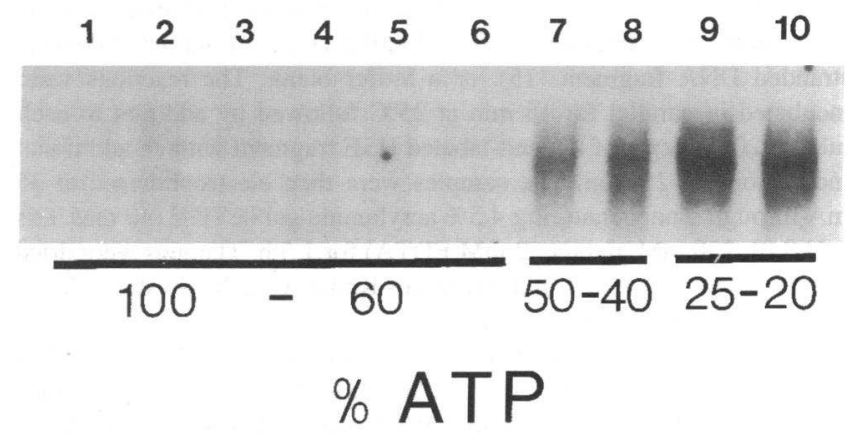

Figure 5. The relationship between cellular ATP and the presence of activated HSF. \% ATP, cellular ATP during the $45 \mathrm{~min}$ occlusion as percent of preocclusion level. The values given are the range within each group of the specific stable ATP levels achieved for each separate sample shown. The bands shown represent HSF-HSE interaction. Free labeled oligonucleotide which migrated to the bottom of the gel is not shown. 

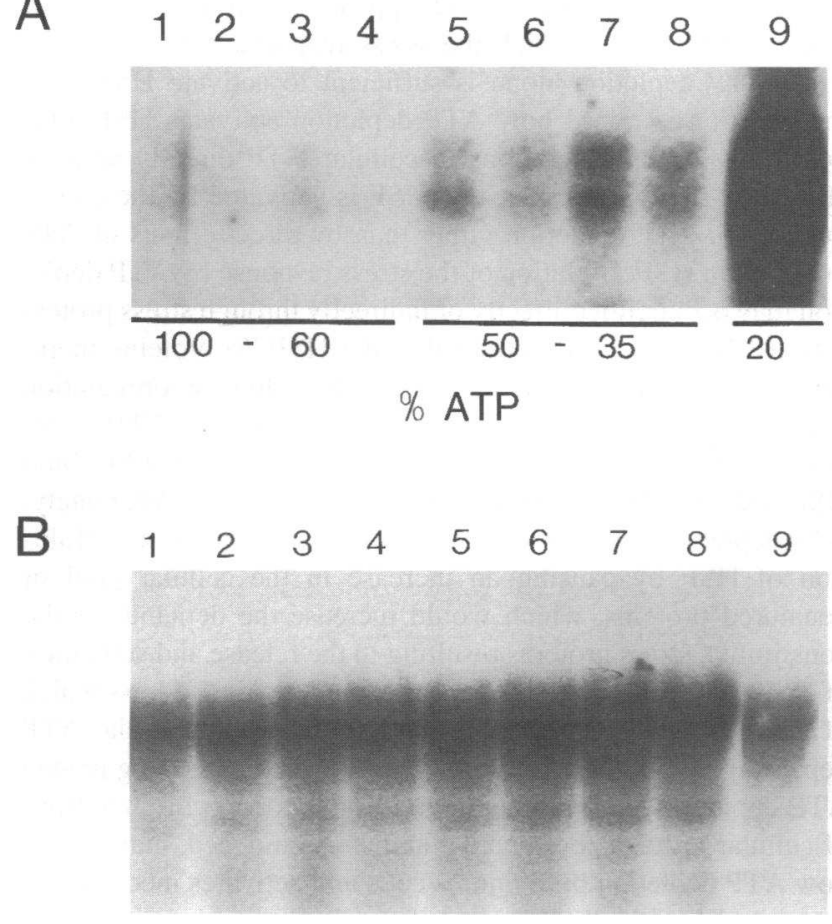

Figure 6. HSP-70 mRNA induction following graded vascular occlusion. (A) Northern blot using a probe for inducible HSP-70 mRNA. RNA samples are from renal cortex through $2 \mathrm{~h}$ of recovery after the occlusion interval. \% ATP, cellular ATP during the occlusion interval. The values given are the range within each group of the specific stable ATP levels achieved for each separate sample shown. $(B)$ Hybridization of the same blot with probe to $28 \mathrm{~S}$ ribosomal subunit to demonstrate RNA loading.

lar ATP (100\%) or graded reduction of cellular ATP down to $60 \%$ control. Basal levels of HSF capable of binding HSE did not change with any reduction in cellular ATP down to $60 \%$ control. Cortical extracts for lanes 7 and 8 were obtained after reduction in cellular ATP to $40-50 \%$ control; for lanes 9 and 10 , extracts were obtained after ATP reduction to $20-25 \%$ control. An increase in activated HSF was first noted when ATP levels were reduced below 50\% control. A more abundant increase in activated HSF was apparent when cortical ATP was reduced to $20-25 \%$ preocclusion.

Since HSF activation is not necessarily followed by HSP70 mRNA transcription (9), a parallel series of experiments were performed to determine whether HSP-70 mRNA induction occurred in this model of energy deprivation and whether the pattern of message elaboration correlated with HSF activation. Northern analysis using a probe for inducible HSP-70 mRNA was performed on total RNA extracted from renal cortex through $2 \mathrm{~h}$ reflow, the time at which HSP-70 mRNA elaboration is most prominent after total vascular occlusion (5). Inducible HSP-70 mRNA as related to cellular ATP levels during aortic constriction is displayed in Fig. 6. Minimal inducible HSP-70 mRNA is present in sham operated kidneys and in those with ATP levels above $60 \%$ preocclusion. Reduction of cellular ATP below $50 \%$ resulted in consistent elaboration of message for the stress protein at $2 \mathrm{~h}$ of reflow. Thus, induction of HSP-70 mRNA during reflow correlated with activation of
HSF prior to reflow when cellular ATP levels were below 50\% preocclusion.

In contrast, a similar relationship between intracellular $\mathrm{pH}$ and the heat-shock response was not observed. Intracellular $\mathrm{pH}$, as determined by NMR spectroscopy, declined in animals in which cortical ATP was less than $50 \%$, but did not decline further when ATP was reduced below $25 \%$ control values, a level at which greater HSF activation and more vigorous HSP70 mRNA induction occurred. Thus, the intensity of the heatshock response was not related to intracellular $\mathrm{pH}$.

\section{Discussion}

The induction of HSP-70 in heat-stressed cells has been found to occur very rapidly through activation of HSF with trimerization and binding of the transcription factor to the HSE (18). Activation of HSF to bind HSE, then, is an early and sensitive indicator of initiation of the stress response. While a host of injurious agents result in stress protein production, the mechanism of induction may not be the same. The pattern of induction varies depending upon the stress applied, and certain agents activate HSF to bind HSE without subsequent transcription of HSP-70 mRNA $(19,20,21,22)$. Benjamin et al., however, have provided evidence that hypoxia in myogenic cells induced HSP70 expression through mechanisms similar to those active in heat shock (23). Since HSF activation, as demonstrated in gelretardation assay, appears to be both a sensitive and early indicator of the stress response, we used this marker to define the relationship of cellular ATP during ischemia to initiation of the stress response.

With maximal ATP depletion, HSF activation occurs rapidly, by $15 \mathrm{~min}$ into the ischemic interval. HSF-HSE interaction during and following 45 min of maximal ATP depletion correlates with the pattern of HSP-70 mRNA accumulation reported previously (5). HSF binding to HSE is found as early as 15 $\mathrm{min}$, is increased at $30 \mathrm{~min}$ of reflow, and has begun to decline by $2 \mathrm{~h}$ of reflow. Following activation of the transcription factor, HSP-70 mRNA accumulation follows a similar sequence: it is first detectable by $15 \mathrm{~min}$ reflow, peaks at $2 \mathrm{~h}$, and has begun to decline at $6 \mathrm{~h}$. HSP-70 mRNA induction is followed shortly thereafter by production of the protein HSP-72, the inducible member of the family (5). This pattern is consistent with the concept that inducible HSP-70 is negatively regulated at the transcriptional level, either through inhibition of HSF activation, or possibly through deactivation of the trimers by the stress protein itself $(17,24,25)$.

Our studies indicate that reflow, and thus reperfusion injury, is not necessary for initiation of this stress response since activated transcription factor was present both at 15 and $45 \mathrm{~min}$ of maximal ATP depletion without reflow. Subsequent reflow, however, could enhance the stress response since greater HSFHSE interaction occurred at 30 min reflow than at the end of ischemia. Jacchini et al. found a similar pattern in ischemicreperfused rat liver (26). Though reactive oxygen molecules have been considered responsible for reperfusion injury (reviewed in 2), they may not be responsible for enhanced stress protein induction during the reflow period since chemical oxidative stress failed to induce expression of the HSP-70 gene in separate studies of oxidative cell injury $(19,26)$. Rather, increased HSP response during reperfusion may flow from the improved metabolic state of the cell which could enhance RNA and protein synthesis both for the stress proteins themselves 
and for other proteins requiring their chaperone activities. In addition, the substantial rebound in ATP levels during early reflow could result in further activation of HSF by release from HSP-70 proteins (24).

The heat-shock proteins appear to have an intimate and multifaceted relationship to cellular ATP. They require ATP hydrolysis for their activity, their state of binding to other proteins depends on the presence or absence of ATP, and they may protect ATP synthesis in stressed cells. Benjamin et al. separated the activation of $\mathrm{HSF}$ from a direct effect of hypoxia itself and from the acidosis that accompanies hypoxia or inhibition of oxidative metabolism (27). They found, instead, that the effects of ATP depletion alone were sufficient to induce HSFHSE interaction. We sought to determine whether a relationship exists between specific decrements in cellular ATP and induction of the stress response in renal cortex, in vivo. Prior to this report, models of ischemia-induced HSP-70 production have relied upon complete vascular occlusion $(5,6)$, severe hypoxia (23), or total metabolic inhibition (27). With glucose deprivation alone, Benjamin found no HSF activation at cellular ATP levels of $50 \%$ control. It was not until severe ATP depletion to $30 \%$ control, achieved by complete inhibition of oxidative phosphorylation, that HSF binding to DNA was observed in cultured myogenic cells. Using a model of graded vascular occlusion and continuous in vivo monitoring to achieve specific steady state decrements in cellular ATP, we evaluated activation of HSF in renal cortex after $45 \mathrm{~min}$ of energy depletion. When ATP levels were maintained above $60 \%$, increased activation of HSF could not be detected; however, increased HSF binding to HSE consistently accompanied reduction in cortical ATP below 50\% preocclusion values. Thus, in renal cortex, cellular ATP levels or the metabolic consequences of energy depletion may be a threshold factor for the induction of the stress response.

In models using cellular toxins $\mathrm{H}_{2} \mathrm{O}_{2}$, sodium salicylate, arsenite, and even heat stress in particular cell types, the earliest indication of the stress response, HSF binding to HSE, is not followed by increased transcription for the $70 \mathrm{kD}$ proteins (1921). We found, however, that in renal cortex HSP-70 mRNA elaboration is closely associated with activation of HSF. Inducible HSP-70 mRNA is present in renal cortex at $2 \mathrm{~h}$ reflow after specific reduction of cellular ATP to below $50 \%$ control, but not at levels above $60 \%$. In addition, subsequent mRNA levels parallel activation of HSF in renal cortex. Increased HSP-70 mRNA is found when more HSF is activated with reduction in cellular ATP to 20-25\%. With higher cellular ATP levels (35$50 \%$ ), less activated HSF is apparent and less HSP-70 mRNA accumulates (Figs. 5 and 6). Such coordination of HSF activation with subsequent transcriptional activity has been described $(11,12,25)$ though not uniformly found $(21,25,28)$. Our results also suggest that the heat-shock response in kidney cortex is a stepped response to energy depletion; initial induction occurs when ATP is reduced below 50\% and a more vigorous stress response is induced with ATP depletion below $25 \%$ control. In contrast, while intracellular $\mathrm{pH}$ declined with partial occlusion, we found no relationship between intracellular $\mathrm{pH}$ and the intensity of the heat-shock response. Unlike the in vitro studies by Benjamin et al. (27), our results do not allow for conclusive separation of cellular $\mathrm{pH}$ changes from ATP depletion. However, our in vivo results are consistent with their conclusion that ATP depletion, not $\mathrm{pH}$, is central to induction of the stress response.
Since in renal cortex there appears to be a threshold of cellular ATP below which the stress response is initiated and since ATP depletion alone is sufficient to activate HSF (27), the question is raised how ATP depletion activates HSF. One possibility is that alterations in cellular ATP directly activate HSF. It is likely, however, that HSF is activated by the consequences of ATP depletion rather than by direct effects of ATP quantity on HSF. Initiation of the stress response by ATP depletion may occur either directly or indirectly through stress protein actions. It has been proposed that the HSP-70 proteins themselves control HSF activation, thus providing autoregulation depending upon cellular needs $(9,10,18)$. Cellular ATP levels could directly affect the ability of constitutive HSP-70 to bind HSF and, thereby, inhibit HSF activation $(17,29)$. Alternately, ATP depletion could indirectly affect the stress proteins' inhibition of HSF by causing an increase in the cellular pool of denatured proteins, which would increase the demand for the constitutive stress proteins resulting in the release and activation of $\operatorname{HSF}(9,30)$. The studies presented here do not address which of these models best represent the path by which cellular ATP depletion leads to HSP-70 induction. However, studying graded ATP depletion and HSF activation in the context of alterations of cellular proteins, both native and stress-induced, may clarify how ATP depletion both injures cells and activates mechanisms that may be critically important for cellular recovery.

\section{Acknowledgments}

We are grateful for the excellent assistance of Marie Campbell and Melanie-Dawn Belanger with manuscript preparation, and of Robert S. Mann with figure preparation.

This work was supported by National Institute of Diabetes and Digestive Kidney Diseases grants DK-44336, DK-38978-04, and DK17433-20; National Institutes of Health Children's Health Research Center grant HD-27757; and a grant from the Charles H. Hood Foundation. This work was done during the tenure of a Clinician-Scientist Award (S. Van Why) from the American Heart Association.

\section{References}

1. Siegel, N. J., P. Devarajan, and S. K. Van Why. 1994. Renal cell injury: metabolic and structural alterations. Pediatr. Res. 36:129-136.

2. Weinberg, J. M. 1991. The cell biology of ischemic renal injury. Kidney Int. 39:476-500.

3. Nover, L. 1991. Heat-shock response. CRC Press, Boca Raton, FL. 509 pp.

4. Skowyra, D., C. Georgopoulos, and M. Zylicz. 1990. The E coli DNA K gene product, the hsp 70 homolog can reactivate heat-inactivated RNA polymerase in an ATP hydrolysis-dependent manner. Cell. 62:939-944.

5. Van Why, S. K., F. Hildebrandt, T. Ardito, A. S. Mann, N. J. Siegel, and M. Kashgarian. 1992. Induction and intracellular localization of HSP-72 after renal ischemia. Am. J. Physiol. 263:F769-F775.

6. Emami, A., J. H. Schwartz, and S. C. Borkan. 1991. Transient ischemia or heat stress induces a cytoprotectant protein in rat kidney. Am. J. Physiol. 260:F479-F485.

7. Nissam, I., M. Hardy, J. Pleasure, I. Nissam, and B. States. 1992. A mechanism of glycine and alanine cytoprotective action: stimulation of stressinduced HSP-70 mRNA. Kidney Int. 42:775-782.

8. Borkan, S. C., A. Emami, and J. H. Schwartz. 1993. Heat stress proteinassociated cytoprotection of inner medullary collecting duct cells from rat kidney. Am. J. Physiol. 265:F333-F341.

9. Morimoto, RI. 1993. Cells in stress: transcriptional activation of heat-shock genes. Science (Wash. DC). 259:1409-1410.

10. Sorger, PK. 1991. Heat-shock factor and the heat-shock response. Cell. 65:363-366.

11. Mosser, D. D., N. G. Theodorakis, and R. I. Morimoto. 1988. Coordinate changes in heat-shock element-binding activity and HSP 70 gene transcription rates in human cells. Mol. Cell Biol. 8:4736-4744.

12. Abravaya, K., B. Phillips, and R. I. Morimoto. 1991. Heat-shock induced 
interactions of heat-shock transcription factors and the human HSP 70 promoter examined by in vivo footprinting. Mol. Cell Biol. 11:586-592.

13. Boydstun, I. I., G. Thulin, X. Zhu, M. J. Avison, K. Gaudio, and N. J. Siegel. 1993. Disassociation of postischemic recovery of renal adenosine triphosphate and cellular integrity. Pediatr. Res 33:595-597.

14. Blake, M. J., R. Udelsman, G. J. Feulner, D. D. Norton, and N. J. Holbrook. 1991. Stress-induced heat-shock protein 70 expression in adrenal cortex: an adrenocorticotropic hormone-sensitive, age dependent response. Proc. Natl. Acad. Sci. USA. 88:9873-9877.

15. Goldenberg, C. J., Y. Luo, M. Fenna, R. Baler, R. Weinmann, and R. Voellmy. 1988. Purified human factor activates heat-shock promoter in a HeLa cell-free transcription system. J. Biol. Chem. 263:19734-19739.

16. Ausubel, F. M. 1993. Current Protocols in Molecular Biology. Wiley Interscience, New York. pp. A.3.11-12.

17. Baler, R., W. J. Welch, and R. Voellmy. 1992. Heat shock gene regulation by nascent polypeptides and denatured proteins: hsp70 as a potential autoregulatory factor. J. Cell Biol. 117:1151-1159.

18. Lis, J., and C. Wu. 1993. Protein traffic on the heat-shock promoter: parking, stalling and trucking along. Cell. 74:1-4.

19. Bruce, J. L., B. D. Price, C. N. Coleman, and S. K. Calderwood. 1993. Oxidative injury rapidly activates the heat-shock transcription factor but fails to increase levels of heat-shock proteins. Cancer Res. 53:12-15.

20. Hensold, J. O., C. R. Hunt, S. K. Calderwood, D. E. Houseman, and R. E. Kingston. 1990. DNA binding of heat-shock factor to the heat-shock element is insufficient for transcriptional activation in murine erythroleukemia cells. Mol. Cell Biol. 10:1600-1608.

21. Jurivich, D. A., L. Sistonen, R. A. Kroes, and R. I. Morimoto. 1992. Effect of sodium salicylate on the human heat-shock response. Science (Wash. DC). 255: $1243-1245$.
22. Liu, R. Y., D. Kim, S. Yang, and G. C. Li. 1993. Dual control of heatshock response: involvement of a constitutive heat-shock element-binding factor Proc. Natl. Acad. Sci. USA. 90:3078-3082.

23. Benjamin, I. J., B. Kroger, and R. S. Williams. 1990. Activation of the heat-shock transcription factor by hypoxia in mammalian cells. Proc. Natl. Acad. Sci. USA. 87:6263-6267.

24. Abravaya, K., M. P. Myers, S. P. Murphy, and R. I. Morimoto. 1992. The human heat-shock protein hsp 70 interacts with HSF, the transcription factor that regulates heat-shock gene expression. Genes \& Dev. 6:1153-1164.

25. Abravaya, K., B. Phillips, and R. I. Morimoto. 1991. Attenuation of the heat-shock response in HeLa cells is mediated by the release of bound heat-shock transcription factor and is modulated by changes in growth and in heat-shock temperatures. Genes \& Dev. 5:2117-2127.

26. Tacchini, L., L. Schiaffonati, C. Pappalardo, S. Gatti, and A. BernelliZazzera. 1993. Expression of HSP-70, immediate early response and heme oxygenase genes in ischemic-reperfused rat liver. Lab. Invest. 68:465-471.

27. Benjamin, I. J., S. Horie, M. L. Greenberg, R. J. Alpern, and R. S Williams. 1992. Induction of stress proteins in cultured myogenic cells. Molecular signals for the activation of heat shock transcription factor during ischemia. $J$. Clin. Invest. 89:1685-1689.

28. Karn, H., N. Ovsenek, and J. J. Heikkila. 1992. Examination of the DNA sequence-specific binding properties of heat-shock transcription factor in Xenopus laevis embryos. Biochem. Cell Biol. 70:1006-1013.

29. Palleros, D. R., W. J. Welch, and A. L. Fink. 1991. Interaction of hsp 70 with unfolded proteins: effects of temperature and nucleotides on the kinetics of binding. Proc. Natl. Acad. Sci. USA. 88:5719-5723.

30. Beckmann, R. P., M. Lovett, and W. J. Welch. 1992. Examining the function and regulation of hsp70 in cells subjected to metabolic stress. $J$. Cell Biol. 117:1137-1150. 